\section{Agency for Toxic Substances and Disease}

Registry. Access: https://www.atsdr.cdc. gov/.

In 1980, Congress created the Agency for Toxic Substances and Disease Registry (ATSDR) as a subdivision of the U.S. Department of Health and Human Services. Its overarching function is to protect the public from harmful chemical exposure through public health assessments of existing and emerging environmental health threats. It also provides guidance to state and local health partners, and educates communities about health effects from hazardous substances.

ATSDR provides a wealth of information on toxicological substances that is regularly reviewed to ensure currency and accuracy. Some of the major resources accessible from the homepage are the "Toxic Substances Portal," "Toxicological Profiles," "Interaction Profiles," and ATSDR publications. There are many other interesting tools and resources provided by ATSDR, such as environmental public health training course material (some accredited) and health widgets such as asthma action plans and FluView, an automated national map of influenza activity.

The "Toxic Substances Portal" serves as a "one-stop-shop" for information about toxic substances. It is arranged by health effects of toxic exposure (e.g., endocrine effects) and chemical classification (e.g., pesticides), audience (e.g., emergency responders and community members), substances A-Z, and state maps where substances are known to be present. It also provides a quick search that not only covers substance names, but also synonyms, tradenames, and Chemical Abstract Service numbers. Each substance has a page devoted to general information that

Joni R. Roberts is associate university librarian for public services and collection development at Willamette University, email: jroberts@willamette.edu, and Carol A. Drost is associate university librarian for technical services at Willamette University, email: cdrost@ willamette.edu provides a brief synopsis: affected organ systems, cancer or health classification, chemical classification, summary of the substance and its use, and a link to an extensive toxicological profile of the substance.

Each substance in the "Toxicological Profile" is peer-reviewed to provide a "comprehensive and extensive evaluation, summary, and interpretation of available toxicological and epidemiological information." The profiles are rich in content, and typically contain hundreds of pages of PDFs

The "Interaction Profiles" investigate how multiple substances interact with each other, such as the combination of lead, manganese, zinc, and copper. Like the toxicological profiles, the information about the interactions can be quite extensive. Information about chemical combinations is still uncommon today, so ATSDR is filling a sorely needed and very important niche within the biomedical, toxicology, and chemistry fields.

Professionals in these fields will find this resource very useful._John Repplinger, Willamette University,jrepplin@willamette.edu

National Coalition for the Homeless. Access:

https://nationalhomeless.org.

Founded in 1981, the National Coalition for the Homeless ( $\mathrm{NCH}$ ) describes itself as a "national network of people," who are committed to ending and preventing homelessness, while supporting those who are currently homeless. Approximately one quarter of the NCH Board has been, or currently are, homeless. The NCH website serves as an information clearinghouse for its core audience: activists, advocates, service providers, and those who are homeless.

The NCH website contains these sections: "Homelessness in America," "About NCH," "Issues," "Campaigns," "Taking Action," and "Resources." The "Homelessness in America" section provides a basic overview of homelessness, such as demographics, geography, and links to additional resources. 


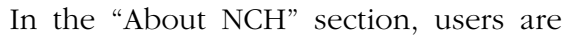
provided with an overall history of the organization, a listing of current Board members, financial information, policy priorities, as well as ways to contact the organization or get involved.

The "Issues" section presents the ten top issues that contribute to homelessness. Each issue is covered in a succinct yet thorough manner. All issues pertaining to homelessness are backed up by sources, many of which come from nonprofit organizations, advocacy groups, and government providers. Each issue closes with information on how to become an advocate, as well as links to support resources.

Those wishing to advocate for homelessness will find a wealth of information in the "Campaigns" and "Taking Actions" sections. Here they will find a listing of national campaigns, information on how to get involved, advice on how to lobby policy makers, and ways to support $\mathrm{NCH}$.

Educators, librarians, and others researching homelessness will find the "Resources" section invaluable. This particular section is further divided into reports, fact sheets, and manuals. The reports are composed of comprehensive full-text PDFs on a given homelessness topic. Each report is well-referenced and includes charts and graphs, in addition to text. Fact sheets are brief overviews of topics related to homelessness and include charts and graphs. Lastly, the manuals serve as a how-to guide for concerned citizens who wish to organize in their communities.

The overall layout of the site is intuitive and easy to navigate. Much of the information is appropriate for its core audience, but students and educators will also find useful information here.-Brad Matthies, Gonzaga University,matthies@gonzaga.edu

Victorian Illustrated Shakespeare Archive. . Access: https://shakespeareillustration.org/.

The Victorian Illustrated Shakespeare Archive contains more than 3,000 illustrations from four complete sets of the works of Shakespeare. The sets are illustrated by Kenny
Meadows, John Gilbert, Henry Courtney Selous, and various illustrators in the set edited by Charles Knight. These sets contain abundant illustrations. This allowed Victorian readers of the plays to "see" the characters and settings, even if they could not view the plays. Michael John Goodman created the Victorian Illustrated Shakespeare Archive as an outcome of his $\mathrm{PhD}$ thesis at Cardiff University.

The archive is easy to use. Under each of the illustrator's (or editor's) names, there is a dropdown menu that allows the user to select from comedies, histories, or tragedies. Each of those categories has a further dropdown menu of play titles. When the user selects a title, thumbnail images are displayed, each of which can be enlarged. Some of the illustrations are on full pages, while others are on pages that contain both illustrations and text.

For each illustration, brief information is given regarding illustrator name, engraver, original size, source of the text, and publishing information. In addition to the illustrator's dropdown menus, there is a general search menu that allows the user to search by acts, characters by name or gender, genre, location, play title, title page, preliminary material, and introductions.

There is also a discussion board and an alphabetical list of words that are linked to illustrations by topics, characters, and objects. For example, if the user clicks on swords, the resulting illustrations all contain images of swords. The illustrations, as expected, are in black-and-white and are beautifully detailed. While there is text on some of the illustrated pages, the archive does not contain the complete texts of the plays. Information is given on how to cite the archive.

The Victorian Illustrated Shakespeare Archive is an excellent resource for those studying art, Shakespeare, or Victorian-era perceptions of literary characters. It is also interesting just to browse the illustrations to see the differences and similarities of the interpretations of the various artists. The archive is a valuable resource for fans of Shakespeare and aficionados of Victorian art.-Mary Wise, Central Washington University, matthies@gonzaga.edu $\mathbf{n}$ 